\title{
The Control Technology Research of the Z-source Three-phase Four-bridge Arm Inverter
}

\author{
Xiangli Li, Zhaoyang Yan , Keke Pan, Chenghao Ma, Hanhong Qi \\ Key Lab of Power Electronics for Energy Conservation and Motor Drive of Hebei Province, \\ Yanshan university, Qinhuangdao, China \\ Email: 1x1@ysu.edu.cn
}

Received March, 2013

\begin{abstract}
Z-source inverter can boost the voltage of the DC-side, allow the two switches of the same bridge arm conducting at the same time and it has some other advantages. The zero-sequence current flows through the fourth leg of the three-phase four-leg inverter so the three-phase four-leg inverter can work with unbalanced load. This paper presents a Z-source three-phase four-leg inverter which combines a Z-source network with three-phase four-leg inverter. The circuit uses simple SPWM modulation technique and the fourth bridge arm uses fully compensated control method. The inverter can maintain a symmetrical output voltage when the proposed scheme under the unbalanced load.
\end{abstract}

Keywords: Z-source Inverter; Three-phase Four-leg inverter; Unbalanced Load; Imbalanced Voltage

\section{Introduction}

Z-source inverter[1-5] with Buck-Boost characteristic can boost the low DC power to a specified high voltage, and the two switches of the same bridge arm can conduct at the same time. Then there is no longer necessary to add the dead zone, thereby Z-source inverter can reduce the harmonic content because of the dead zone setting, and improve the quality of the power conversion. The traditional three-phase inverter can not provide pathways for the zero sequence current which is generated by unbalanced load, It is only suitable for balanced load. Three-phase four-bridge arm inverter[6-7] increases a bridge arm on the basis of the traditional three-bridge arm inverter structure. And this bridge arm constitutes midline and then eliminates the need of the midpoint transformer when the load is unbalanced, reduces the volume and weight of the system. Dq0 rotating coordinate variables are mutually orthogonal, there is no coupling, they can be individually controlled, but the disadvantage of this method is the large amount calculation of the coordinate transformation and coordinate inverse transformation[8]. The paper separates the fourth bridge arm from the other control coupled bridge arm. The fourth bridge arm is individually controlled. Based on the advantages of the $Z$-source network and three-phase four-bridge arm inverter, this paper presents $Z$ source three-phase four- bridge arm inverter, and it can improve the voltage pressure, under the unbalanced load it is able to maintain a good symmetrical output voltage.

\section{Analysis of the Main Circuit}

\subsection{The Main Circuit}

The main circuit is shown in Figure 1. Z-source impedance network is provided by the diode $\mathrm{D}$, capacitor $\mathrm{C} 1$, $\mathrm{C} 2$ and inductors L1, L2.In the design of the $\mathrm{Z}$ impedance network, the capacitance value of $\mathrm{C} 1, \mathrm{C} 2$ is equal and the inductance value of L1, L2 is equal. And the formula is $\mathrm{C} 1=\mathrm{C} 2=\mathrm{C}, \mathrm{L} 1=\mathrm{L} 2=\mathrm{L}$.

The fourth bridge arm of the three-phase four- bridge arm inverter is added to the traditional three-phase three arms. The fourth bridge arm consists of switching tube $\mathrm{Q}_{7}, \mathrm{Q}_{8}$. The midpoint of the bridge arm connects the inductor $\mathrm{L}_{\mathrm{n}}$ to the load neutral point. The main function of the inductance $L_{n}$ is to filter the switching ripple of the neutral current. $Z$-source network and three-phase fourbridge arm inverter are combined to form a $Z$-source three-phase four-bridge arm inverter. The DC voltage Udc boost by the Z-source network then changes into alternating current through the four-leg inverter then the alternating current powers the unbalanced load through the LC filter.

\subsection{Working Principle of Z-source Inverter}

Z-source inverter has two working conditions which are the active state and the shoot-through state. The inverter can be equivalent to a controlled current source $i_{\text {in }}$.

Figure 2(a) shows the active working state of the Zsource inverter's equivalent circuit diagram. When the 
switching state is one of the active state or the traditional zero vector, the input of the diode $\mathrm{D}$ is conducting, the power source and the inductors $\mathrm{L}_{1}, \mathrm{~L}_{2}$ simultaneously power the load, capacitor $\mathrm{C}_{1}$ and $\mathrm{C}_{2}$ are charging status.

Figure 2(a) can be obtained:

$$
\begin{aligned}
& u_{d c}=u_{C_{1}}+u_{L_{2}}=u_{C_{2}}+u_{L_{1}} \\
& u_{i n}=u_{C_{1}}-u_{L_{1}}=u_{C_{2}}-u_{L_{1}}=u_{C}-u_{L}
\end{aligned}
$$

Calculate the above two formulas, we can obtain:

$$
u_{\text {in }}=2 u_{C}-u_{d c}
$$

where $u_{i n}$ is the DC side input voltage .

Figure 2(b) shows the shoot-through working state of the Z-source inverter's equivalent circuit diagram. Diode $\mathrm{D}$ is cutoff. Inductor and capacitor exchange energy. Capacitance charges inductance .We can obtain from Figure 2 (b):

$$
\begin{aligned}
& u_{C_{1}}=u_{C_{2}}=u_{C}=u_{L_{1}}=u_{L_{2}}=u_{L} \\
& u_{\text {in }}=0
\end{aligned}
$$

The inductor $\mathrm{L}_{1}\left(\mathrm{~L}_{2}\right)$ should satisfy the volt-second characteristic within a switching period $\mathrm{T}_{\mathrm{s}}$ (the average storage energy of a switching cycle is zero). During a switching cycle, anti-shoot-through state works time is
$\mathrm{T}_{1}$, shoot- through state works time is $\mathrm{T} 0$, and $\mathrm{T} 1+\mathrm{T} 0=$ $\mathrm{T}_{\mathrm{s}}, \mathrm{d}_{0}$ is the straight-through duty cycle. Then we can obtain:

$$
\begin{aligned}
& \left(u_{d c}-u_{C}\right) T_{1}+u_{C} T_{0}=0 \\
& u_{C}=\frac{T_{1}}{T_{1}-T_{0}} u_{d c}=\frac{1-d_{0}}{1-2 d_{0}} u_{d c} \\
& u_{i n}=\frac{1}{1-2 d_{0}} u_{d c}
\end{aligned}
$$

It can be seen that when $\mathrm{T}_{0}$ varies within the range of $0-0.5 \mathrm{~T}, \mathrm{U}_{\mathrm{in}} / \mathrm{U}_{\mathrm{dc}}$ is theoretical from 1 to infinity.

\subsection{The Simple Boost SPWM Modulation Me- thod}

The basic idea of the $Z$ source three-phase inverter SPWM modulation is as follows. When Z-source inverter works in traditional zero vector state and shoot-through zero vector state, the three-phase load is short-circuited. Replace the part time of the traditional zero vector time with the shoot-through zero vector time, keep the effective vector works time the same, and then can increase the output voltage value of the $\mathrm{Z}$-source inverter. The modulation principle is shown in Figure 3.

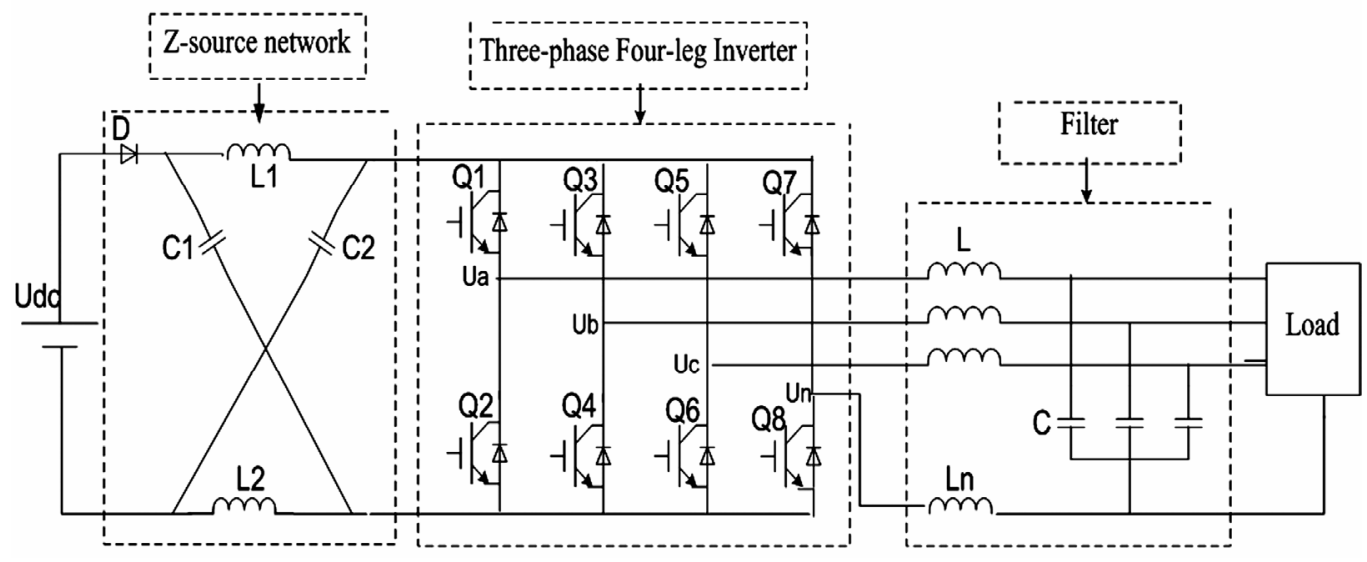

Figure 1. The main circuit topology of Z-source three-phase four-leg inverter.

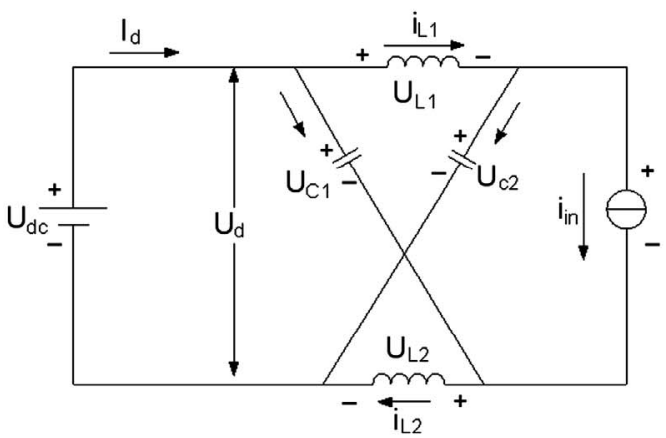

(a) Active state

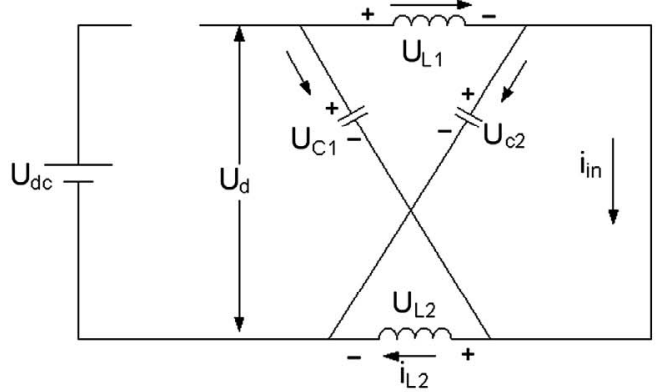

(b) Shoot-through state

Figure 2. The status of the Z-source inverter. 


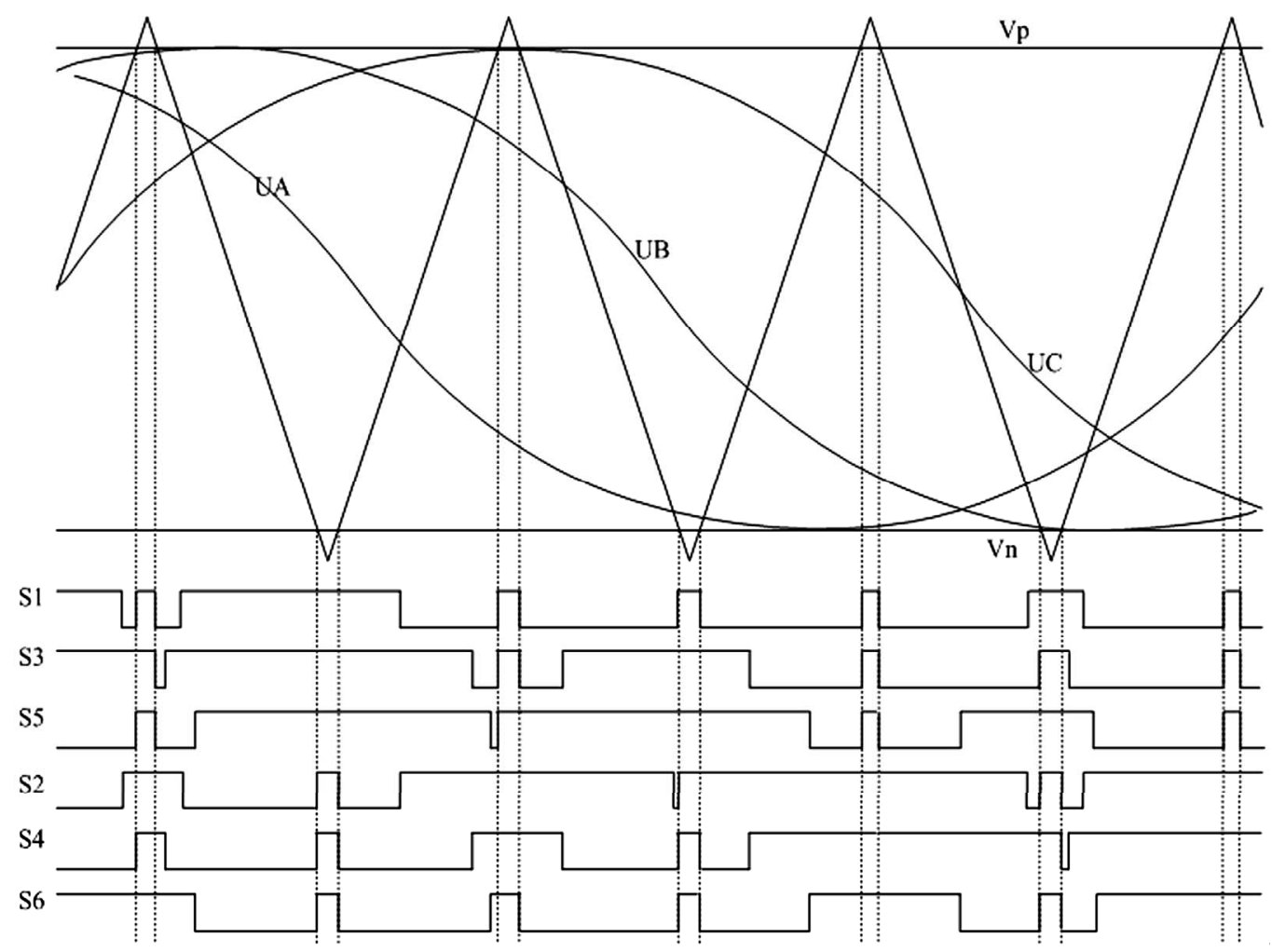

Figure 3. Simple boost SPWM modulation technology schematic.

In Figure 3, $V_{p}$ is equal to or greater than the peak value of the three-phase reference voltage, and $V_{n}$ is equal to or smaller than the carrier negative peak voltage. They are used to control the straight duty cycle. When the carrier amplitude is higher than $V_{p}$ or lower than $V_{n}$, the inverter operates in the shoot-through zero state, when the carrier amplitude is between $V_{p}$ and $V_{n}$, the inverter is in the traditional SPWM modulation state.

Can be obtained, $\mathrm{D}_{0}$ will be reduced when the modulation factor $M$ increases. The maximum value of $D_{0}$ of is (1-M), when $M$ is $1, D_{0}$ is 0 . The output phase voltage amplitude of inverter is:

$$
\begin{gathered}
u_{\mathrm{a}, \mathrm{b}, \mathrm{c}}=M \times \frac{u_{i n}}{2}=M B \times \frac{u_{\mathrm{dc}}}{2}=G \times \frac{u_{\mathrm{dc}}}{2} \\
B=\frac{1}{1-2 d_{0}}=\frac{1}{2 M-1} \\
G=M * B=\frac{M}{2 M-1}
\end{gathered}
$$

$\mathrm{U}_{\text {in }}$ is the DC side of the inverter input voltage. $B$ is the boosting factor. $\mathrm{M}$ is the modulation factor of the inverter. $\mathrm{G}$ is a gain factor.

By the formula (1) and formula (2), knowing that the arbitrary size's AC output voltage can be obtained by controlling the $\mathrm{d}_{0}$ and $\mathrm{M}$. It expands the conversion range of the entire system, and is applicable to more applications.

\subsection{The Fourth Leg Control Principle}

Figure 4 is a circuit diagram of the three-phase fourbridge arm inverter.

$\mathrm{i}_{\mathrm{a}}+\mathrm{i}_{\mathrm{b}}+\mathrm{i}_{\mathrm{c}}=0$ when three-phase three- bridge arm inverter with three-phase linear balanced load. $\mathrm{u}_{\mathrm{an}}, \mathrm{u}_{\mathrm{bn}}, \mathrm{u}_{\mathrm{cn}}$ are determined by $u_{a}, u_{b}, u_{c}, i_{a}+i_{b}+i_{c} \neq 0$. When the three-phase four-bridge arm inverter with unbalanced load, $\mathrm{u}_{\mathrm{an}}, \mathrm{u}_{\mathrm{bn}}, \mathrm{u}_{\mathrm{cn}}$ are jointly decided by $\mathrm{u}_{\mathrm{a}}, \mathrm{u}_{\mathrm{b}}, \mathrm{u}_{\mathrm{c}}$ and $\mathrm{u}_{\mathrm{n}}$.

Assumptions:

$$
\left\{\begin{array}{l}
u_{a}=m_{\mathrm{a}} \sin (\omega t-\theta) \\
u_{b}=m_{b} \sin (\omega t-\theta-2 \pi / 3) \\
u_{c}=m_{c} \sin (\omega t-\theta-4 \pi / 3)
\end{array}\right.
$$

$\mathrm{L}_{\mathrm{n}}=\mathrm{L}$, by the formula (3) can be obtained

$$
\begin{aligned}
u_{a}+u_{b}+u_{c}= & L d i_{n} / d t+\left(u_{A G}+u_{B G}+u_{C G}\right) \\
& +3\left(u_{\mathrm{n}}+L d i_{n} / d t\right)
\end{aligned}
$$

If $u_{a}+u_{b}+u_{c}=0$, then

$$
L d i_{n} / d t+\left(u_{A G}+u_{B G}+u_{C G}\right)+3\left(u_{\mathrm{n}}+L d i_{n} / d t\right)=0
$$

If the fourth bridge arm's un is designed to be

$$
u_{\mathrm{n}}=-4 / 3 * L d i_{n} / d t
$$

Then

$$
u_{A G}+u_{B G}+u_{C G}=0
$$

Output voltage is balanced. 
In the actual control, $\mathrm{k}\left(u_{A G}+u_{B G}+u_{C G}\right)$ items is add to adjust the three-phase asymmetry.

\section{Three-phase Output Voltage Control}

\subsection{Mathematical Model of the Three-phase Four-leg Inverter under the Three-phase Rotating Coordinate System (d, q, 0)}

Differential equations of the three-phase four-bridge arm according to Figure $\mathbf{4}$ can be listed as follows:

$$
\begin{gathered}
L \frac{\mathrm{d}}{d t}\left[\begin{array}{l}
I_{a} \\
I_{b} \\
I_{c}
\end{array}\right]=L_{n} \frac{d}{d t}\left[\begin{array}{l}
I_{n} \\
I_{n} \\
I_{n}
\end{array}\right]+\frac{U_{\text {in }}}{2}\left[\begin{array}{l}
d_{a} \\
d_{b} \\
d_{c}
\end{array}\right]-\left[\begin{array}{l}
U_{A G} \\
U_{B G} \\
U_{C G}
\end{array}\right] \\
C \frac{d}{d t}\left[\begin{array}{l}
U_{A G} \\
U_{B G} \\
U_{C G}
\end{array}\right]=\left[\begin{array}{l}
I_{a} \\
I_{b} \\
I_{c}
\end{array}\right]-\left[\begin{array}{l}
I_{o a} \\
I_{o b} \\
I_{o c}
\end{array}\right]
\end{gathered}
$$

Among them $d_{a}, d_{b}$, dc are three-phase phase voltage duty cycles, $I_{a}, I_{b}, I_{c}$ are output phase current of the inverter. $I_{o a}, I_{o b}$ and $I_{o c}$ are three-phase load current. $I_{n}$ is the neutral inductor current. $U_{\text {in }}$ is the $\mathrm{DC}$ side input voltage of the inverter.

Stationary coordinate system $(a, b, c)$ changes to the rotating coordinate system $(\mathrm{d}, \mathrm{q}, 0)$ coordinates. The transformation matrix is as follows.

$$
T_{\mathrm{abc} / d q 0}=\frac{2}{3}\left[\begin{array}{ccc}
\sin \omega t & \sin \left(\omega t-\frac{2 \pi}{3}\right) & \sin \left(\omega t+\frac{2 \pi}{3}\right) \\
\cos \omega t & \cos \left(\omega t-\frac{2 \pi}{3}\right) & \cos \left(\omega t+\frac{2 \pi}{3}\right) \\
1 / 2 & 1 / 2 & 1 / 2
\end{array}\right]
$$

The correspondence relationship between the abc coordinate physical quantity with dq0 coordinate physical quantity is as follows.

$$
\begin{aligned}
& {\left[\begin{array}{lll}
U_{d} & U_{q} & U_{0}
\end{array}\right]^{T}=T_{\mathrm{abc} / d q 0}\left[\begin{array}{lll}
U_{A G} & U_{B G} & U_{C G}
\end{array}\right]^{T}} \\
& {\left[\begin{array}{lll}
I_{d} & I_{q} & I_{0}
\end{array}\right]^{T}=T_{\mathrm{abc} / d q 0}\left[\begin{array}{lll}
I_{a} & I_{b} & I_{c}
\end{array}\right]^{T}} \\
& {\left[\begin{array}{lll}
I_{\text {od }} & I_{o q} & I_{o 0}
\end{array}\right]^{T}=T_{\mathrm{abc} / d q 0}\left[\begin{array}{lll}
I_{o a} & I_{o b} & I_{o c}
\end{array}\right]^{T}} \\
& {\left[\begin{array}{lll}
d_{d} & d_{q} & d_{0}
\end{array}\right]^{T}=T_{\mathrm{abc} / d q 0}\left[\begin{array}{lll}
d_{a} & d_{b} & d_{c}
\end{array}\right]^{T}}
\end{aligned}
$$

Consolidate the formula (4) (5) (6) (7) can be obtained.

$$
\begin{gathered}
\frac{d}{d t}\left[\begin{array}{l}
I_{d} \\
I_{q} \\
I_{0}
\end{array}\right]=\frac{U_{\mathrm{dc}}}{2} M\left[\begin{array}{l}
d_{d} \\
d_{q} \\
d_{0}
\end{array}\right]-M\left[\begin{array}{l}
U_{d} \\
U_{q} \\
U_{0}
\end{array}\right]-\omega\left[\begin{array}{l}
-I_{\mathrm{q}} \\
I_{\mathrm{d}} \\
0
\end{array}\right] \\
C \frac{\mathrm{d}}{d t}\left[\begin{array}{l}
U_{d} \\
U_{q} \\
U_{0}
\end{array}\right]=C \omega\left[\begin{array}{l}
U_{q} \\
-U_{d} \\
0
\end{array}\right]+\left[\begin{array}{l}
I_{d} \\
I_{q} \\
I_{0}
\end{array}\right]-\left[\begin{array}{l}
I_{L d} \\
I_{L q} \\
I_{L 0}
\end{array}\right]
\end{gathered}
$$

where the matrix $\mathrm{M}$ is

$$
M=\left[\begin{array}{ccc}
\frac{1}{L} & 0 & 0 \\
0 & \frac{1}{L} & 0 \\
0 & 0 & \frac{1}{3 L_{n}+L}
\end{array}\right]
$$

From the formula (8) and (9) we can obtain the coupling between the dq axis, 0 axes is independent. Feed forward compensation is used to release the coupling between the dq axis, after decoupling, after decoupling, d-axis, q-axis, 0 axes are the three single-input singleoutput independent control system.

Under the dq0 rotated coordinate system, inductor current loop is the inner loop; the capacitor voltage loop is the outer loop. The controlled schematic diagram is shown in Figure 5 as below:

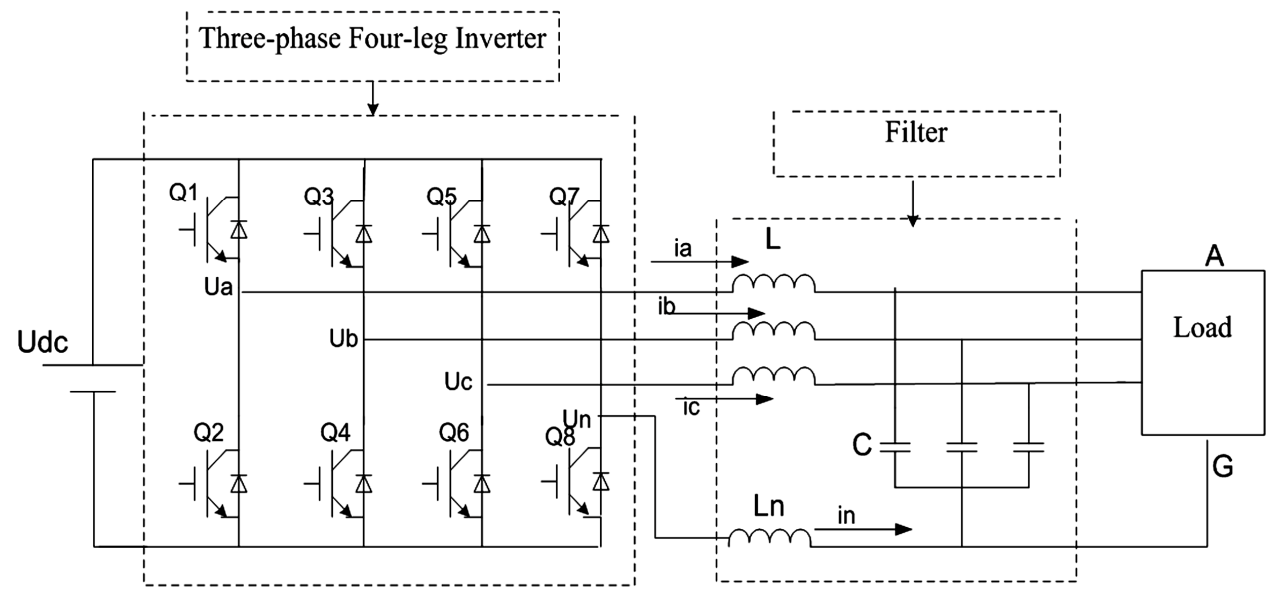

Figure 4. Three-phase four-leg inverter structure diagram. 

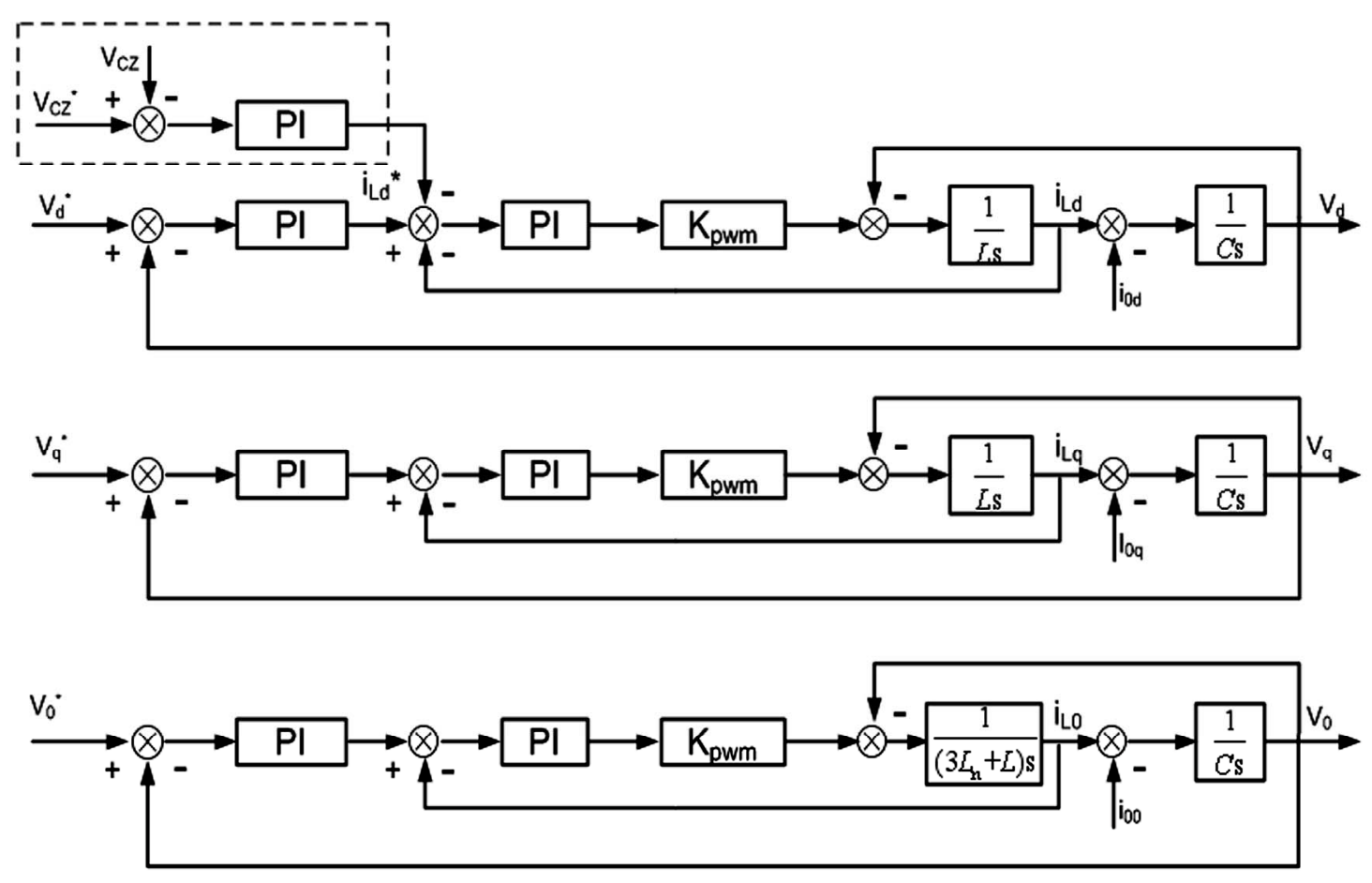

Figure 5. dq0 axis control schematic structure diagram.

\subsection{Z-source Network Capacitor Voltage Control Design Idea}

Here is the controlled method of Z-source network capacitor voltage. The Z-source network capacitor voltage control block diagram is shown in Figure 5. In the design of the capacitor voltage out loop, the current inner loop is regarded as a gain link in the out loop path. Ignoring the inverter bridge own loss under the condition of unity power factor, the active power of the inverter $\mathrm{AC}$ side is equal to the active power of the inverter circuit DC side, then we can obtain the formula (11).

$$
u_{i n} i_{\text {in }}=\frac{3}{2} u_{\mathrm{a}} i_{a}=\frac{3}{2} u_{\mathrm{d}} i_{d}+\frac{3}{2} u_{\mathrm{q}} i_{q}
$$

In order to simplify the design of the controlled system, $\mathrm{q}$ axis vector voltage was regarded as the 0 vector voltage in the two-phase synchronous rotating coordinate system (d, q). so formula (11) is converted into formula (12).

$$
u_{i n} i_{i n}=\frac{3}{2} u_{\mathrm{a}} i_{a}=\frac{3}{2} u_{\mathrm{d}} i_{d}
$$

There are formulas (13), (14) of the Z-source network as follows.

$$
\begin{gathered}
u_{i n}=2 u_{c}-u_{d c}=\frac{1}{1-2 d_{0}} u_{d c} \\
i_{i n}=i_{Z L}-i_{C}
\end{gathered}
$$

According to formula (13) and formula (14), formula
15 can be obtained. Where $u_{\text {in }}$ is the DC side of the inverter input voltage, $i_{\text {in }}$ is the DC side of the inverter input current, $u_{d c}$ is the power supply of the system. $i_{\mathrm{ZL}}$ is the current in the inductor Z-source network.

$$
i_{c}=i_{Z L}-i_{i n}=i_{Z L}-\frac{3}{2} \frac{u_{d} i_{d}}{u_{i n}}=i_{Z L}-\frac{3}{2} \frac{u_{d} i_{d}\left(1-2 d_{0}\right)}{u_{d c}}
$$

So capacitor current $i_{c}$ of the voltage loop can be controlled by controlling the load AC current $i_{d}$ and thus control the capacitor voltage.

\section{The Simulation Results}

System simulation parameters are as follows:

Three-phase output phase voltage: $110 \sqrt{2} / 50 \mathrm{~Hz}$

Input voltage of the DC side: $330 \mathrm{~V}$

Three-phase filter inductor: $1 \mathrm{mH}$

Midline inductance: $1 \mathrm{mH}$

Filter capacitor: $25 \mu \mathrm{F}$

Z-source network inductance: $2 \mathrm{mH}$

Z-source network capacitor: $3300 \mu \mathrm{F}$

The next two cases were analyzed: (1) the $Z$ source three-phase three-leg with unbalanced load (two-phase no-load, one phase with a load of 50 ohms) (2) Z-source three-phase four-leg with unbalanced load(two-phase noload, one phase with a load of $50 \mathrm{ohms}$ ).

From Figure 6, we can see the output waveforms quality is poor and the load voltage is unbalanced when Z-source three-phase three-bridge arm inverter circuit is with unbalanced load. 

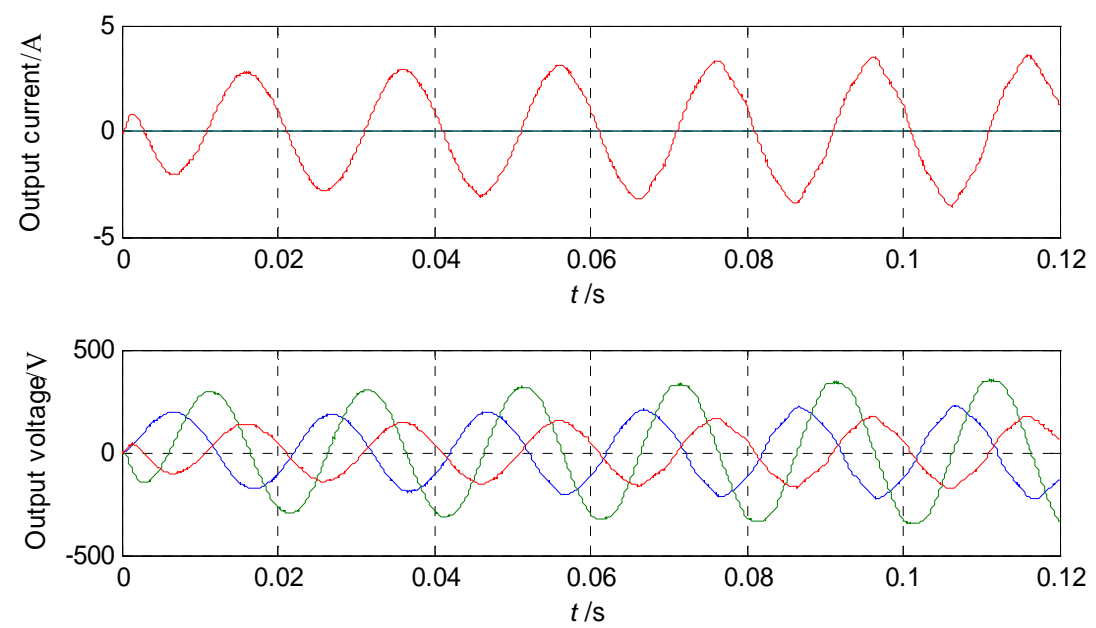

Figure 6. Three-phase three-leg simulation waveforms with unbalanced load.
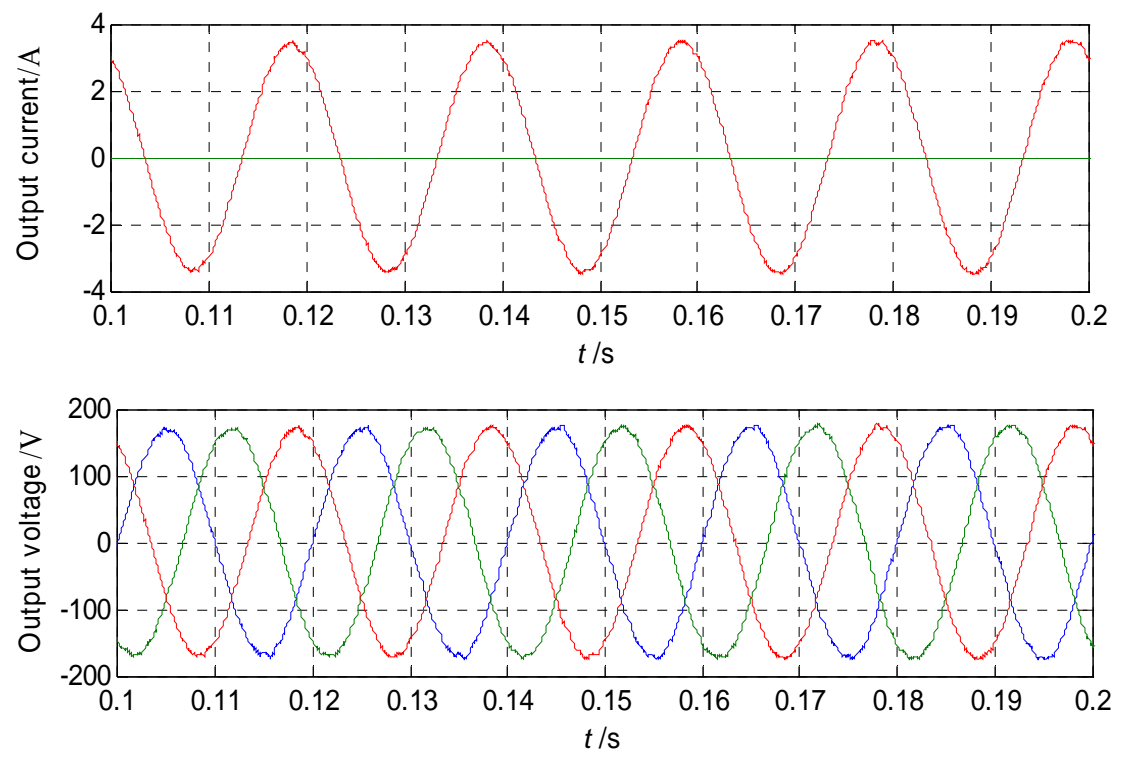

Figrue 7. Three-phase four-leg with unbalanced load simulation.

From Figure 7, we can see the waveforms in the Zsource three-phase four-bridge arm inverter system with the same load have been greatly better. The degree of imbalance of output voltage is small. But the amplitude does not have a very good stability in expectation; there is a growing trend, so the control mode needs to improve.

\section{Conclusions}

This paper presents a Z-source three-phase four-bridge arm inverter which combines a Z-source network with three-phase four-leg inverter. The circuit uses simple SPWM modulation technique. The three-phase fourbridge arm use PI control in synchronous rotating coordinate system, the fourth bridge arm use independent methods to control. The simulation results demonstrate the Z-source three-phase four-bridge arm inverter can output three-phase sine wave voltage under unbalanced load conditions.

\section{REFERENCES}

[1] F. Z. Peng, X. P. Fang, B. Gu, et al., "Z-Source Converter," Transactions of China Electrotechnical Society, Vol. 19, No. 2, 2004, pp. 47-51.

[2] M. S. Shen, J. Wang, F. Z. Peng, et al., "Maximum Constant Boost Control of the Z-source Inverter," IEEE Industry Applications Society Annual Meeting, 2004, pp. 142-147.

[3] E. Wit and J. McClure, "Statistics for Microarrays: Design, Analysis, and Inference," 5th Edition, John Wiley \& Sons Ltd., Chichester, 2004. doi:10.1002/0470011084

[4] X. P. Ding, Z. M. Qian, B. Cui, et al., "Fuzzy PID Controller for DC-link Boost Voltage in Z-source In- 
verter," Proceedings of the CSEE, Vol. 28, No. 24, 2008, pp. 31-38.

[5] P. C. Loh, D. M. Vilathgamuwa, C. J. Gajanayake, Y. R. Lim and C. W. Teo, "Transient Modeling and Analysis of Pulse-Width Modulated Z-Source Inverter," EEEE Transaction on Power Electronics, Vol. 22, No. 2, 2009, pp. 498-507.

[6] L. B. Li, Z. G. Zhao, et al., "Study on three-phase photovoltaic grid-connected inverter system based on compositive control," Power System Protection and Control, 2010 , Vol. 38, No. 21, pp. 44-47.
[7] L. Jun, T. C. Green and C. Feng, "Increasing Voltage Utilization inSplit-Link, Four-Wire Inverters," IEEE Trans. on Power Electronics," Vol. 6, No. 24, 2009, pp. 1562-1569.

[8] P. C. Loh, D. M. Vilathgamuwa, C. J. Gajanayake, L. T. Wong, C. P. Ang, "Z-Source Current-Type Inverters: Digital Modulation and Logic Implementation," IEEE_Transactions on Power Electronics, Vol. 22, No. 1, 2007, pp. 169-177. doi:10.1109/TPEL.2006.886618 